\title{
Barriers of HIV treatment-seeking behavior among youths living with HIV in Uganda: a qualitative study
}

\author{
Anthony Kiwanuka ${ }^{1}$, Eddy Walakira ${ }^{1}$, Lena Andersson ${ }^{2}$, David Kaawa Mafigiri ${ }^{1}$ \\ ${ }^{1}$ Makerere University, Kampala, Uganda \\ ${ }^{2}$ Gothenburg University, Gothenburg, Sweden
}

\begin{abstract}
Introduction: This study aimed to explore experienced barriers to seek human immunodeficiency virus (HIV) treatment and care among youth living with HIV and acquired immunodeficiency syndrome (AIDS) in Uganda. Given that this population remains at the center of HIV epidemic, the study's ultimate goal was to contribute to improvement of effectiveness of HIV prevention interventions for youth in Uganda. Twenty in-depth interviews were conducted with HIV-infected youth aged between 18 and 24 , who had entered care within one year upon receipt of results and referral for free care. In addition, key-informant interviews were conducted with 30 health service providers. The study used thematic content analysis to analyze its' findings. The study demonstrated that barriers to using HIV care included fear of stigma and HIV disclosure, young men and women's lack of support from their families, demanding work schedules, and high transport costs. Programmatic barriers included fear of stigma, antiretroviral drug side effects, long waiting and travel times, and inadequate service providers' respect for patients. The study recommends targeted interventions to combat stigma, strengthen couple counseling and health education programs, and address gender inequalities among other things.

Material and methods: We conducted 20 in-depth interviews among HIV-infected individuals aged between 18 and 24 years and key-informant interviews.

Results: Barriers to using HIV care included, among others, fear of stigma and HIV disclosure, and young men and women's lack of support.

Conclusions: Targeted interventions to combat stigma, strengthen couple counseling and health education programs, focus on gender inequalities as well as implement youth-friendly and flexible clinic service hours are all needed to address barriers to using care of HIV patients.
\end{abstract}

HIV AIDS Rev 2022; 21, 1: 43-49

DOI: https://doi.org/10.5114/hivar.2022.112711

Key words: treatment, HIV, youth, Uganda, seeking behavior.

\section{Introduction}

Millions of people have been infected with human immunodeficiency virus (HIV) during the past four decades. The absence of effective HIV prevention and treatment

Address for correspondence: Anthony Kiwanuka, Makerere University, Kampala, Uganda, e-mail: akiwanuka@gmail.com

efforts means that more people will be affected. Stigma and discrimination are some of the greater enemies in the battle against HIV and acquired immunodeficiency syndrome (AIDS). HIV and AIDS stigma and discrimination are important factors that need to be addressed to create an effec-

Article history:

Received: 09.03.2021

Revised: 12.04.2021

Accepted: 21.06.2021

Published: 15.01.2022
International Journal of HIV-Related Problems

HIV \& AIDS

R e v i e w 
tive response to HIV and AIDS prevention and treatment. Unlike other conditions, knowledge of HIV status comes with physical, emotional, social, and legal concerns [1]. Therefore, it is very important to explore reasons that constitute for HIV and AIDS stigma and discrimination, their effects on HIV and AIDS responses as well as measures to reduce these effects.

HIV and AIDS have reached epidemic proportions in most parts of sub-Saharan Africa. In 2014, 20.8 million HIV and AIDS patients were recorded in this region, which was equivalent to two-thirds of the global total for that year [2].

Making high-risk groups the priority for preventive interventions at the earliest stage of the epidemic has been viewed as an important strategy for HIV and AIDS, because it targets the right population at the 'right' time. In subSaharan Africa, where youths now constitute the main pool affected by the epidemic, the role of youth-specific interventions aimed at preventing HIV and AIDS stigma cannot be overestimated $[2,3]$.

Generally, stigma has been described as a negative reaction to an attribute in an individual that is deemed as undesirable or discrediting in a social or societal setting [4]. It is compared to societal power structures when one group of individuals develops prejudicial thoughts and behaviors toward another group of individuals who share a particular attribute [5]. In the context of HIV and AIDS, HIV and AIDS-related stigma consists of unfavorable attitudes, beliefs, and policies directed toward people perceived to have HIV and AIDS, and with regard to their loved ones, associates, and communities [5]. The youth who know their status and are able to access treatment experience several challenges, including disclosure, stigma and discrimination, and lack of support to help them to maintain on treatment. Finding optimal antiretroviral regimens and supporting that improve clinical and social help and care can be critical in reducing AIDS-related deaths in young generation; this requires a holistic and life-long approach $[2,5]$.

All over the world, HIV and AIDS-related stigma and discrimination are of growing concern. At the same time, self or internal stigma is one of the influential factors that make people living with HIV and AIDS (PLWHA) feel ashamed and guilty about their positive status. However, stigma has been largely ignored by existing policies of some sub-Saharan countries [6]. Stigma can deter or delay testing and disclosure. Moreover, in many countries, counseling is not considered a crucial support for testing services and

Table 1. Socio-demographic characteristics of participants $(N=50)$

\begin{tabular}{l|c|c}
\hline Respondent category & $n$ & Age group, years \\
\hline Youths living with HIV/AIDS & 20 & $18-24$ \\
\hline Health providers & 10 & $\geq 25$ \\
\hline Parents & 10 & $\geq 40$ \\
\hline Teachers & 10 & $\geq 30$ \\
\hline
\end{tabular}

stimulated coping by denial and/or secrecy about their HIV status. In Botswana, HIV patients survey on antiretroviral therapy (ART) found that $40 \%$ had delayed being tested for HIV because of stigma. Stigmatizing attitudes perpetuate the belief that HIV can also reduce the amount of people testing, as people who are less likely to believe they are at risk. Another study found that men with more stigmatizing beliefs were less likely to had an HIV test [7]. Stigma often prevents disclosure of HIV-positive status to partners, providers, and family members, who would prevent behaviors that can further spread HIV, such as condom use, or mitigate its' impact, i.e., care seeking [8]. Therefore, this study explored the psycho-social, environmental, and socio-cultural factors, which influence HIV help-seeking behavior among youth living with HIV. The notion of double stigma is conjectured to be an added burden that face young populations in the sub-Saharan region, but may impact disparate cultural groups in various countries of Africa.

\section{Material and methods}

\section{Study design}

This study adopted qualitative research approaches that rely on inductive inquiry, beginning with a worldview and ending with data analysis [9]. The approach provides the ability to gather in-depth information about the research topic, and enables acquiring full and rounded understanding of youths' experiences of stigma and situations pertaining to HIV and AIDS treatment-seeking behavior [10].

\section{Study setting}

The study was conducted in Kampala, the capital city of Uganda. Kampala has five divisions: Central, Lubaga, Kawempe, Nakawa, and Makindye, and the study sites were located in Nakawa and Makindye. Although Kampala has many health facilities, within this study, only two health facilities were selected, namely Naguru Teenage Clinic and Nsambya Mother Care Health Center. These health facilities provide comprehensive, quality health services, and specialized care and treatment for people living with HIV and AIDS, including adults.

\section{Study participants and sampling}

Demographic characteristics of participants included 20 youth living with HIV and AIDS, aged between 18 and 24 years, and 30 key informants, namely teachers, parents, and health service providers, as indicated in Table 1.

Much as it was difficult to get participants, an effort was made to reach them and explain the purpose of the study. Purposive and convenience sampling were used to recruit participants because of rich diversity of the target population. Their diverse backgrounds and experiences provided diverse perceptions and experiences of stigma. However, within this 
homogeneity, diversity in terms of age, length of time since diagnosis, country of origin, and gender were sought.

Weakness of this sampling technique was found when appropriate informants were not willing to disclose some sensitive information, although they were assured about confidentiality. Data was analyzed qualitatively in line with key themes of the study, using content and thematic analysis techniques. First step in the analysis of data consisted of reviewing and categorizing textual data under different themes that were of study's interest. Interpretative phenomenological analysis (IPA) was also used in the study. From a qualitative perspective, the study was limited to 20 in-depth interviews. The interviews were conducted by the researcher at clinical centers. Coding of data collected started immediately after the interviews were transcribed. This process involved working with the interview data, organizing it, dividing it into manageable units, synthetization, and searching for patterns to discover what was important for the study. Analysis started with identification of themes emerged from raw data, a process sometimes referred to as 'open coding. During open coding, the researcher identified and tentatively named conceptual categories, into which the phenomena observed were grouped.

\section{Study procedures}

The researcher, with the help of social workers, identified and recruited potential informants. Most of these informants were determined through convenience sampling. Willing informants met with the researcher to learn more about the purpose of the study. Informants who consented were invited for interviews and discussions at the times of mutual convenience.

The study used an interview guide with open-ended questions to identify the impact of stigma on HIV treatment-seeking behavior among the youths, and explore their perceptions, effects of stigma in their lives, and their HIV and AIDS treatment-seeking behaviors. Validity of the data was ensured, as the instruments were first pre-tested.

\section{Data analysis}

After the data collection process, information was organized for analysis. Kansiime [11], cited in Kvale [12], states that transcription itself is an interpretative process. Therefore, the informant's experiences of different phenomena in the interviews were transcribed verbatim. Quotations were also given in their original shape to retain vivid reality of the respondents. The interview material was analyzed from a phenomenological perspective to understand information from the informants' own perspectives and experiences, how they describe the world, and how they experience it [12]. Furthermore, data was analyzed qualitatively based on key themes of the study, using content and thematic analysis techniques. Interviews and focus group sessions were conducted to reach data saturation.

\section{Ethical consideration}

Given the sensitivity of the subject under study, no reference was given to specific identities of the respondents/ participants to assure confidentiality of their responses. Informed consent from participants and agencies were obtained, and participants had the right to withdraw from the study or not to answer a particular question. Written approvals by the Makerere University School of Social Sciences research ethics committee (MAKSS REC) and the Uganda National Council of Science and Technology (UNCST) were obtained.

\section{Trustworthiness}

Trustworthiness of the study was ensured by credibility, transferability, dependability, and conformability as suggested by Shenton (2004). First, credibility was ensured by adopting well-established research methods previously used in qualitative data. Second, a pilot study to gain familiarity with the culture of participants and organizations prior to the study was performed to establish understanding of the phenomenon and trust. Third, triangulation of data by using in-depth face-to-face interviews, field notes, and observations were done; and lastly, qualified and experience investigators were employed. In-depth account of the study's background and description of the phenomenon allowed for transferability. Dependability was ensured through explicitly accounting for the study site, criteria for participants' inclusion, sample size, data collection methods, data collections procedure, and the time period, in which the study was conducted, so that the study may be replicated. Finally, conformability was ensured by reduction of researcher's bias through the use of bracketing, provision of in-depth methodological procedures, and acknowledgement of limitations of the study.

\section{Results}

The research findings presented a depressing picture. Fear of stigma and discrimination was found to pervade all spheres of life from home to workplace, clinics, and community. Stigma and discrimination tended to be internalized by most of the youth living with HIV and AIDS, and could cause serious problems on their respective emotional and physical well-being. This section presents major findings based on the in-depth individual and key informants' interviews.

\section{Fear of stigma and discrimination}

The youth described HIV and AIDS as 'Walumbe', 'slim, 'Kawuka', and 'Kavera, which literally mean 'death', 'slim, 'virus', and 'polythene paper', respectively. The responses showed that HIV and AIDS is commonly associated with death. The issue was that there is no cure; therefore, it leads to death at any time. Furthermore, HIV and AIDS is associ- 
ated with fornication, prostitution, adultery, or extra marital sexual relationships. "The public opinion is always negative", according to the informants. "It becomes shocking to get news that so and so is HIV and AIDS-positive".

"Public sees the victims as being promiscuous, being a mobile grave - a nickname given to a person who may die any time, fear of not being employed, especially when their jobs are in places like United Arab Emirates (AUE)." (Female participants No. 1, 3).

When asked on the barriers of HIV treatment-seeking behavior, the key informants agreed that HIV stigma affects HIV and AIDS treatment-seeking behavior among the youth.

"They fear to go for HIV and AIDS testing because they fear to be known by their friends. In case results come out positive, they feel the status can cause rejection by their peers. In schools and institutions, students prefer to deal with nurses instead of dealing with teachers and administrators. (...) Some teachers behave unprofessionally and rebuke students in public. Students try to avoid such teachers."

\section{Isolation}

The participants said that isolation was the pre-dominant reaction to HIV. According to them, stigma is used to marginalize and exclude youth who are living with HIV and AIDS. Cautiousness from fear of infection also leads people to prevent their children from having contact with those known to be living with HIV and AIDS. In addition, some family members of those living with HIV and AIDS try to prevent them from doing casual housework, such as preparing food for the family. If a person has HIV, it is also assumed that the person is already dead; therefore, they cannot take part in any decision-making process in the family. Unfortunately, specific eating utensils are designated to those living with HIV when their families discovered that they were HIV-positive; this isolate and makes youth living with HIV and AIDS very vulnerable. Apart from stigma-related issues, the following questions were asked to the study participants:

- Have you experienced any social interaction changes when you knew about your status?

- Are there any positive events that have helped sustaining your life since the time you were diagnosed with HIV and AIDS?

- Do you know of anyone or a group of people who have not helped to live positively since the time you were diagnosed with HIV and AIDS?

- Are you satisfied with HIV treatment and care services for youth in your community? If no, would you share the reasons why?

\section{Insults, labeling with various names, and gossiping}

Gossiping, verbal harassment or ridicule, and ostracism toward people living with HIV were highlighted.
"People living with HIV have particular fears about disclosure and knowing whom to trust. There is silence around HIV because of gossiping and labeling." (Male participants No. 4,2$)$.

The participants reported that it was important for them to test for HIV; however, they were afraid of what would happen to them afterwards. Therefore, this fear of 'what could happen' acted as a barrier to testing.

\section{Testing and beliefs}

The participants in all individual interviews highlighted the need for youth to 'know their status'.

"Nowadays, it is important to know your status. I think he must get tested because you may think that you are negative, whilst you are not." (Female respondent).

Despite this reported belief, few participants had personally been through a counseling and testing process and knew their HIV status. A single female participant reported having wanted his boyfriend to accompany her for testing, but he refused. Three young men reported having been tested for HIV as part of routine testing and counseling for recruitment of joining the army.

\section{Behavior after testing negative or positive}

Findings indicated that youth might not change their sexual behaviors upon learning their HIV status. For example, a negative diagnosis would give youth a false confidence that they can engage in high-risk behavior and 'get away with it'. Some young people perceived HIV-negative diagnosis as a reason for celebration with relatively little thought about future sexual behavior and amelioration of risk (behavioral reactions to an HIV-negative diagnosis - celebration without behavior change).

"According to me, when he finds out that he is negative, he will continue with past actions he used to do, and thinking there is no such thing as HIV/ AIDS." (Phase 1, female participant).

A small number of participants were well-informed about issues, such as window period, and were aware of the need to test again if one had had unprotected sex (behavioral reactions to HIV-negative diagnosis - behavior change). They warned other youths about the potential need for re-testing to make sure that their negative results were accurate.

\section{Testing as a remedy}

The respondents were less likely to discuss changes in sexual behaviors after a positive diagnosis than they were to discuss social consequences of HIV infection. A small number of participants discussed the need to change of sexual behavior, especially through condom use or abstinence. Interestingly, a number of participants indicated that knowing 
one's HIV status would encourage them becoming involved in HIV health services and care.

"Someone's behavior will change in a positive way. She/ he will start to be more responsible about her/his sexual lifestyle, and use protection every time she/he has sex. He or she will start to educate his/her parents, friends, and the community about the virus, and particularly his/her peers who are ignorant about HIV and AIDS." (Female participant).

\section{Disclosure}

Some participants had a feeling that they would disclose to parents and/or family members before any other group or friends. They indicated that being HIV-positive is a disgrace to the family and the community. Even though parents and family members might get angry, they would offer support and could be trusted to keep results a secret from others.

"The family is better for disclosure because they can keep that thing within the family." (Male participant).

A few participants feared the ongoing negative consequences of disclosing to parents or relatives that would not be resolved.

"A father or a relative would not understand. He/she will ask how I got this sickness. He/she will even call me 'Satan'. I think he/she would even chase me away from the house. He will not care where I go. Even the aunt/mother would be a lion (furious)." (Female participant).

The study revealed that friends were the next most popular group to disclose to; however, the youth expressed greater reservations about disclosing to close friends compared to family members. Friends were considered important because they provided a shoulder to lean on. However, there were certain worries that some friends might disclose their HIV status results to others, which would cause gossiping that is more harmful than the potential emotional support from a friend.

"I think that he will go to a friend instead of any family member because he will need someone who can com- fort him... So, the friend will be the only person he will tell. A best friend will advise him to do something about his health." (Female participant).

Partners were the least group mentioned with regard to disclosure. For the respondents, such disclosure was problematic because discovering one's HIV-seropositive status has implications for a sexual relationship, particularly regarding issues of trust and blame. Disclosure to partners was seen as a significant source of anxiety. Although some participants acknowledged that disclosing to family and friends had the potential for rejection and discrimination, they also perceived it as potentially carrying additional consequences of abandonment and loss of possibility for marriage and children. One male participant illustrated:

"There is a higher risk involved for me to go for testing because my girlfriend might leave me to face the situation alone if I test HIV-positive... If I were positive and she is negative, that means she is going to dump me and look for a better one who is HIV-negative. I would be left alone".

Most of the participants agreed to the idea of counseling as a potential solution to get tested and disclosing results to partners.

\section{Family support and care}

The parents indicated that they would need to be a resource for their HIV-positive children, as seen in Table 2. However, they questioned their abilities to provide care, and noted that they would also need counseling to assist in accepting, coping, and caring for their HIV-positive children.

\section{Discussion}

Although youth participants in these interviews referred to the importance of HIV testing, and actual experiences with HIV treatment and care, there was a perception that testing was only necessary for people with symptoms and

Table 2. Themes, process themes, and main categories

\begin{tabular}{|c|c|c|}
\hline Main categories & Process themes & Themes \\
\hline Perceived stigma & $\begin{array}{l}\text { Obstacles or disparities that impede access to } \\
\text { facilities and/or activities that facilitate } \\
\text { or promote HIV stigma, non-burdens }\end{array}$ & $\begin{array}{l}\text { Social stigma } \\
\text { Self-stigma } \\
\text { Family and relative rejection } \\
\text { Friends and community rejection }\end{array}$ \\
\hline Internal stigma & $\begin{array}{l}\text { Problem-focused strategies, emotional coping } \\
\text { strategies, seeking spiritual guidance, and } \\
\text { social support }\end{array}$ & Individual-isolation \\
\hline Healthy system stigma & $\begin{array}{l}\text { Treatment places, services, and offered level } \\
\text { of utilization }\end{array}$ & $\begin{array}{l}\text { Discrimination in receiving health services } \\
\text { Insult from health system staff } \\
\text { Ignorance in providing services }\end{array}$ \\
\hline Poverty & $\begin{array}{l}\text { Lifestyle, standard of living, or cultural burdens, } \\
\text { disparities that impede access to information, } \\
\text { social support, and resources that facilitate } \\
\text { or promote HIV prevention }\end{array}$ & Lack of food, transport to collect medicine \\
\hline
\end{tabular}


signs of AIDS. These perceptions about voluntary counseling and testing were in contrast to actual testing experiences among the youth in other African countries. For example, research carried out in Uganda and Kenya reflected similar views. However, youth said that knowing one's status generally was the reason for testing rather than showing symptoms of the disease (Table 2).

Testing during advanced HIV infection creates the perception that HIV testing always results in a positive diagnosis, and may contribute to the perception that finding out one's status speeds one's death. This causes increased stigma and fear of HIV testing and perpetuates the belief that healthy-looking individuals cannot be HIV-positive, as illustrated in Table 2. Research in South Africa has repeatedly shown that young people have low levels of perceived HIV risk [13-16]. The perception that voluntary counseling and testing (VCT) is for the ill may be a manifestation of the inability of young people to accurately assess their risk of HIV infection [17].

Negative perceptions of healthcare professionals working in VCT and reproductive health centers are consistent with themes in the available literature from developed and developing countries $[7,18]$. Youth in four American cities noted that attitudes of healthcare professionals heightened their anxiety about testing, and stated that they found risk assessment questions embarrassingly personal and intrusive [18]. Kenyan and Ugandan youth most commonly indicated that they desired a 'kind' person to conduct voluntary counseling and testing [7]. Valdiserri et al. suggested that counseling that is more appropriate would increase the rate of youth return for post-test services. As seen in Table 2, conversations with these South African youths show that they too would like VCT testing and counseling to be conducted with sensitivity and kindness in a less medical model than currently used $[7,19]$.

Another study reported that persons to whom youth were able to disclose their status were supportive and responded positively, suggesting that young people may disclose to individuals within their network who they expect to be supportive [7]. Studies from the United States showed that adolescents were most likely to disclose to their parents rather than sexual partners $[20,21]$. In South Africa, fears of rejection, gossiping, and discrimination among HIVpositive women disclosing to partners were reported, but they also indicated that disclosure was more common in partnerships characterized as loving and trusting [22]. Youth participants in this study were afraid of all these factors. Moreover, they were concerned about partner violence, abandonment, sexual abstinence, and losing opportunities for marriage and children [23]. In a study [24], it was suggested that couples counseling can be highly effective in overcoming problems associated with sharing test results and issues of blame. Youth participants in this study highlighted their preference for couples counseling to overcome many of their perceived obstacles to partner's disclosure.

Fears about social consequences of HIV infection, particularly stigma, appeared to be significant barriers to ac- cessing VCT, as demonstrated in Table 2. The participants mentioned stigma-associated factors, including stereotyping, separation, status loss, and discrimination [25] as reasons for avoiding testing (Table 2). Stigma from community members was particularly significant for participants, and was reflected in the fact that no mention was made of community care and support for HIV-infected individuals [26].

The recurring mention of suicide and continued risk behaviors after a negative diagnosis are important dynamics to consider in the provision of VCT for the youth in Uganda. Programs must ensure that they maintain vigilance on these issues, and provide sufficient care, support, and referral services in place to assist HIV-infected youth to manage depression and anxiety, so that uninfected youth are adequately advised on maintaining safe sexual behaviors through their life-changing sexual relationships [19].

Whether access to treatment reduces barriers to treatment, including stigma (through reducing fear of imminent death) and increases sexual risk taking, are the questions, which have started to be investigated in the context of developing countries. However, there is no recent literature on this topic for developing countries [27].

It is important to recognize that the youth in Uganda are not a homogeneous group. Their experiences vary according to many factors, including cultural environment, tribes, gender, socio-economic status, and educational background. For many, the stigma they face in relation to their sexual and reproductive health intersect during their daily lives with other kinds of stigma derived from different forms of social inequality. For example, a young unemployed man having sex with other men in a low-income urban neighborhood is likely to experience stigma from a variety of sources. Therefore, tackling stigma requires addressing its' underlying causes [27]. Research suggests these causes are consistent across different contexts, and include lack of awareness of stigma and its' damaging effects, fear of acquiring HIV through everyday contact, and values linking people with HIV to a behavior considered improper and immoral. "These drivers of stigma can be addressed with any target group by creating awareness of what stigma is and why it is beneficial to reduce it, fostering motivation for change, addressing fears and misconceptions about transmission of HIV, discussing 'taboo' topics that are linked to and fuel HIV stigma and discrimination, such as gender, violence, sexuality, and injecting drug use, and providing the skills to challenge stigma and to change behavior" [8].

The above findings and discussion were aligned and premised on cognitive behavioral model (Beck, 1986), which helps describe to patients how a person's thoughts and feelings interact and eventually, result in a behavior. Cognitive behavioral theory (CBT) requires that patients have a strong understanding of the model that the theory is based upon, and the use of this visual guide will help them achieve that goal. In line with cognitive behavioral model, it was theorized in this study that youths' perceptions about stigma attached with HIV/AIDS treatment greatly determine the extent, to which they would seek HIV/AIDS treatment-seeking 
behaviors. Negative cognitions about stigma attached to HIV treatment would imply that they would not seek this treatment, and positive behaviors would mean that stigma people hold about HIV treatment-seeking behaviors would be eroded from youths.

\section{Conclusions}

It was evident from the study that barriers to using HIV care included fear of stigma and HIV disclosure, young men and women's lack of support from their families, demanding work schedules, and high transport costs. This benchmarked the experienced barriers to seek HIV treatment and care among the youth living with HIV and AIDS in Uganda. Notwithstanding the magnitude of HIV epidemic and central role played by young people in sub-Saharan Africa, the apparent lack of stigma-focused interventions in Uganda calls for more research and scrupulous use of available resources to inform the design and delivery of well-tailored interventions, to meet the unique needs of this population in communities [28]. Once a contextual framework for the intervention is established, future research projects employing a systematic approach are urgently needed to help reverse the course of AIDS pandemic [28]. Understanding the role of stigma being a barrier and testing intervention geared toward reducing stigma would be essential components in such projects [29].

\section{Conflict of interest}

The authors declare no conflict of interest.

\section{References}

1. Anderson M, Elam G, Gerver S, Solarin I, Fenton K, Easterbrook P. "It took a piece of me": initial responses to a positive HIV diagnosis by Caribbean people in the UK. AIDS Care 2010; 22: 1493-1498.

2. Mavedzenge SMN, Doyle AM, Ross DA. HIV prevention in young people in sub-Saharan Africa: a systematic review. J Adolescent Health 2011; 49: 568-586.

3. Paul-Ebhohimhen VA, Poobalan A, Van Teijlingen ER. A systematic review of school-based sexual health interventions to prevent STI/HIV in sub-Saharan Africa. BMC Public Health 2008; 8: 4.

4. Goffman E. Stigma: Notes on the Management of Spoiled Identity. A Spectrum Book. Englewood Cliffs, NJ: Prentice-Hall; 1963.

5. Martinez J, Harper G, Carleton RA, et al. The impact of stigma on medication adherence among HIV-positive adolescent and young adult females and the moderating effects of coping and satisfaction with health care. AIDS Patient Care STDS 2012; 26: 108-115.

6. Sultan B, Benn P, Waters L. Current perspectives in HIV post-exposure prophylaxis. HIV/AIDS (Auckl) 2014; 6: 147-158.

7. Horizons H. Voluntary Counseling and Testing Among Youth: Results from an Exploratory Study in Nairobi Kenya and Kampala and Masaka Uganda. Washington DC: International Center for Research on Women Population Council; 2001.

8. Wagner GJ, Aunon FM, Kaplan RL, et al. Sexual stigma, psychological well-being and social engagement among men who have sex with men in Beirut, Lebanon. Cult Health Sex 2013; 15: 570-582.

9. Creswell JW, Hanson WE, Clark Plano VL, Morales A. Qualitative research designs: Selection and implementation. The Counseling Psychologist 2007; 35: 236-264.
10. Denzin NK, Lincoln YS (eds.). The SAGE Handbook of Qualitative Research. SAGE Publications Inc.; 2011.

11. Kansiime P. The obstacle of HIV/AIDS related stigma and discrimination in HIV prevention, care and treatment in Sweden; a study of People Living with HIV/AIDS and service providers; 2010.

12. Kvale S. InterViews: An introduction to qualitative research interviewing. London: Sage Publications; 1996.

13. Moodley C, Phillips J. HIV/AIDS-related knowledge and behaviour of FET college students: implications for sexual health promotion: lifestyle and risk behaviour. African Journal for Physical Health Education, Recreation and Dance 2011; 17: 49-60.

14. Winskell K, Obyerodhyambo O, Stephenson R. Making sense of condoms: social representations in young people's HIV-related narratives from six African countries. Soc Sci Med 2011; 72: 953-961.

15. MacPhail C, Pettifor A, Moyo W, Rees H. Factors associated with HIV testing among sexually active South African youth aged 15-24 years. AIDS Care 2009; 21: 456-467.

16. Pettifor A, O’Brien K, MacPhail C, Miller WC, Rees H. Early coital debut and associated HIV risk factors among young women and men in South Africa. Int Perspect Sex Reprod Health 2009; 35: 82-90.

17. Sabin C, Gumley H, Youle M, Smith C, Lampe F, Phillips A. Late presenters with HIV in the era of HAART: How effective is therapy. Paper presented at the XV International AIDS conference, Bangkok, Thailand; 2004.

18. Aragón R, Kates J, Greene L, Hoff T. The AIDS epidemic at 20 years: the view from America. A national survey of Americans on HIV/ AIDS. Henry J. Menlo Park: Kaiser Family Foundation; 2001.

19. Valdiserri RO, Ogden LL, McCray E. Accomplishments in HIV prevention science: implications for stemming the epidemic. Nat Med 2003; 9: 881.

20. Dowshen N, D’Angelo L. Health care transition for youth living with HIV/AIDS. Pediatrics 2011; 128: 762-771.

21. Rotheram-Borus MJ, Lee M, Zhou S, et al. Variation in health and risk behavior among youth living with HIV. AIDS Educ Prev 2001; 13: 42-54.

22. Sigxashe TA, Baggaley R, Mathews C. Attitudes to disclosure of HIV status to sexual partners. South Afr Med J 2001; 91: 908-909.

23. Coates T, Richter L, Caceres C. Behavioural strategies to reduce HIV transmission: how to make them work better. Lancet 2008 ; 372: 669-684.

24. Idele P, Gillespie A, Porth T, et al. Epidemiology of HIV and AIDS among adolescents: current status, inequities, and data gaps. J Acquir Immune Def Syndr 2014; 66 Suppl 2: S144-S153.

25. Link BG, Phelan JC. Conceptualizing stigma. Ann Rev Soc 2001; 27: 363-385

26. Arnold EA, Rebchook GM, Kegeles SM. 'Triply cursed': racism, homophobia and HIV-related stigma are barriers to regular HIV testing, treatment adherence and disclosure among young Black gay men. Cult Health Sex 2014; 16: 710-722.

27. Castro A, Farmer P. Understanding and addressing AIDS-related stigma: from anthropological theory to clinical practice in Haiti. Am J Public Health 2005; 95: 53-59.

28. Rhodes T, Singer M, Bourgois P, Friedman SR, Strathdee SA The social structural production of HIV risk among injecting drug users. Soc Sci Med 2005; 61: 1026-1044.

29. Young People and HIV/AIDS: Opportunity in Crisis. United Nations Children's Fund, Joint United Nations Programme on HIV/ AIDS and World Health Organization; 2002. 